\title{
PROPRIEDADES E APLICAÇÕES RECENTES DAS CICLODEXTRINAS
}

\author{
Cristina de Garcia Venturini, Jaqueline Nicolini, Clodoaldo Machado e Vanderlei Gageiro Machado*
}

Departamento de Química, Universidade Regional de Blumenau, CP 1507, 89010-971 Blumenau - SC, Brasil

Recebido em 22/9/06; aceito em 22/5/07; publicado na web em 26/2/08

\begin{abstract}
PROPERTIES AND RECENT APPLICATIONS OF CYCLODEXTRINS. Cyclodextrins (CDs) are cyclic oligosaccharides comprised of six or more glucose units connected by $\alpha-1,4$ bonds. They have hydrophobic cavities with a hydrophilic exterior, and are versatile receptors for a variety of substrates. This ability allows them to be applied in many fields, as distinct as supramolecular chemistry, nanotechnology, pharmaceuticals, green chemistry, agrochemicals, analytical chemistry, toiletries, foods, and cosmetics. This review summarizes several aspects related to the physico-chemical properties of CDs and discusses their potential applications illustrated by recent examples. The prospects for their use in several areas are also described.
\end{abstract}

Keywords: cyclodextrins; molecular recognition; inclusion complexes.

\section{INTRODUÇÃO}

Ao longo das últimas décadas, as ciclodextrinas (CDs) vêm despertando grande interesse na comunidade científica e na química de macromoléculas, sendo descritas como "moléculas sedutoras, atraindo a atenção dos investigadores tanto no campo de pesquisa como no campo de tecnologias aplicadas". Szejtli afirmou que "dentre todas as moléculas receptoras em potencial, as CDs parecem ser as mais importantes"2. Tal afirmação deriva primordialmente do fato das mesmas, por pertencerem à família dos oligossacarídeos macrocíclicos, formarem complexos do tipo receptor-substrato servindo como um ambiente único para reações químicas ${ }^{3}$ e possuírem a habilidade para formar complexos de inclusão com uma variedade de substâncias que têm suas propriedades alteradas pela complexação ${ }^{4}$. Por este motivo, as CDs vêm sendo muito utilizadas em produtos industriais, tecnológicos e em métodos analíticos. Como os efeitos tóxicos podem ser eliminados ou reduzidos pela seleção da $\mathrm{CD}$ apropriada, as CDs podem ser utilizadas como ingredientes de fármacos, em alimentos ou em cosméticos ${ }^{2}$.

As CDs são formadas durante a ação de enzimas denominadas como CD glicosiltransferases (CGTases) sobre o amido ${ }^{5}$, sendo este o processo utilizado na produção industrial das mesmas. Usualmente, os polissacarídeos servem como precursores de oligos-sacarídeos cíclicos. Como resultado, a variedade de oligossacarídeos cíclicos naturais ou semi-sintéticos é limitada ${ }^{6}$. As mais importantes CDs apresentando ocorrência natural são as $\alpha-, \beta$ - e $\gamma$-CDs, que possuem 6, 7 e 8 monômeros de glicose, respectivamente (Figura 1). As características estruturais das mesmas são conhecidas com base em investigações por cristalografia de raios-X no estado sólido e por estudos de RMN em solução. Estas moléculas possuem forma assemelhada a um cone, com uma cavidade de 7,9 $\AA$ de profundidade. Os diâmetros superior e inferior da cavidade das CDs são 4,7 e 5,3 para a $\alpha-C D, 6,0$ e $6,5 \AA$ para a $\beta-C D$ e 7,5 e $8,3 \AA$ para a $\gamma-\mathrm{CD}^{7}$. As CDs modificadas surgiram a partir da tentativa de alterar ou melhorar suas estruturas a fim de obter complexos de inclusão adequados a vários setores, como industrial, alimentício e farmacêutico ${ }^{8}$, e assim um largo número de CDs modificadas tem sido sintetizado ${ }^{6,89}$.

As CDs foram descobertas por Villiers ${ }^{10} \mathrm{em} 1891$, a partir da digestão de $1000 \mathrm{~g}$ de amido com Bacillus amylobacter. Ele obte-

*e-mail: gageiro@furb.br

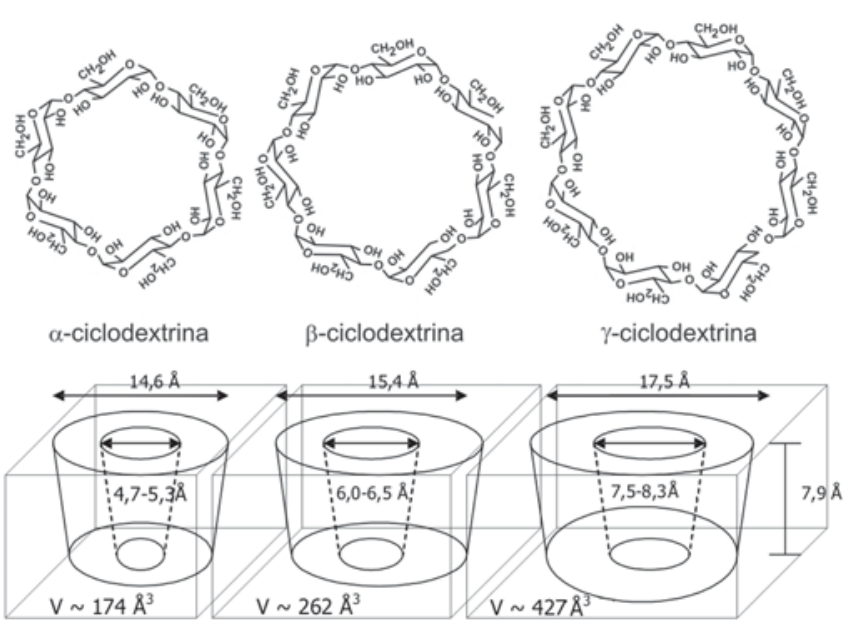

Figura 1. Estrutura e propriedades de $\alpha$-, $\beta$ - e $\gamma-C D$

ve cerca de 3 g de uma substância cristalina, a qual denominou "celulosina", por suas características semelhantes à celulose no que diz respeito à resistência à hidrólise ácida e porque não era redutora. Villiers determinou que a composição desta substância deveria ser $\left(\mathrm{C}_{6} \mathrm{H}_{10} \mathrm{O}_{5}\right)_{2} \cdot 3 \mathrm{H}_{2} \mathrm{O}$ e na forma cristalina ainda pôde observar que ocorriam duas "celulosinas" distintas formadas provavelmente de $\alpha$ - e $\beta$-CDs. Apesar do trabalho pioneiro de Villiers, as CDs foram primeiramente detalhadas por Schardinger ${ }^{11}$ em 1903, que descreveu o processo de preparação e isolamento das mesmas. Por isso, elas são também conhecidas, embora não seja recomendado pela IUPAC, como dextrinas de Schardinger ${ }^{12}$. Ele ainda teve o mérito de distinguir $\alpha$ - e $\beta$-CDs através da reação com iodo ${ }^{11}$. De 1930 a 1970 foram realizados estudos sistemáticos sobre CDs e seus complexos de inclusão. Um grupo composto por Freudenberg e outros estudiosos concluiu, na segunda metade da década de 30, que as CDs apresentam estrutura cíclica ${ }^{13}$. Ao final da década de 60 , o domínio do método de preparação de CDs em escala de laboratório e o acúmulo de informações sobre sua estrutura, propriedades físico-químicas e propriedades de formação de complexos de inclusão levaram a estudos aprofundados visando particularmente suas possíveis aplicações. No entanto, a obtenção das CDs ainda apresentava custo elevado e sua utilização em humanos era discutível, uma vez que aparentemente apresentavam toxicidade elevada ${ }^{2}$. Apenas 
a partir de 1970 a pretensa toxicidade das CDs foi desmentida após estudos toxicológicos adequados, o que motivou um aumento significativo nas pesquisas nesta área. A descrição da estrutura e propriedades das CDs e suas aplicações têm motivado um grande número de pesquisas e publicações neste campo ${ }^{12}$.

Neste trabalho, serão enfatizadas aplicações recentes, assim como as perspectivas, envolvendo o uso das CDs em processos analíticos, ambientais, supramoleculares e industriais. A fim de que se possa compreender melhor aquelas aplicações, faz-se conveniente uma breve visita às três subseções que vêm a seguir, tratando da formação de complexos de inclusão com o uso de CDs como moléculas receptoras, de abordagens para os mecanismos que regem a formação destes complexos receptor-substrato e de trabalhos que buscam explorar a natureza da cavidade das CDs.

\section{COMPLEXOS DE INCLUSÃO}

As CDs formam complexos relativamente não específicos com uma grande variedade de substratos e a principal condição é que o substrato possa se adaptar à cavidade, ainda que parcialmente. Devido a esta habilidade, estas macromoléculas vêm sendo utilizadas como protótipos para investigação de interações não covalentes envolvendo diferentes compostos. Assim, uma grande variedade de substratos, desde gases nobres a derivados de benzeno, corantes aromáticos e água podem ser encontrados inclusos em $\mathrm{CDs}^{14}$. Quanto à estequiometria do complexo de inclusão, são considerados quatro tipos mais comuns de complexo CD: substrato com 1:1, 1:2, 2:1 e 2:2, dependendo do tamanho e aspecto estrutural do substrato em relação à cavidade da $\mathrm{CD}^{15}$.

É geralmente constatado que o fenômeno de reconhecimento molecular, o qual envolve interações não covalentes, deriva de interações tais como ligações de hidrogênio, interações eletrostáticas, forças de van der Waals, efeito hidrofóbico, interações dipolo-dipolo, transferências de cargas e efeitos estéreos ${ }^{15,16}$. A discriminação estereosseletiva, durante a formação do complexo, emerge das diferenças que o substrato em potencial apresenta para se adaptar à cavidade da CD e o ajuste espacial é considerado o fator mais importante para reger o processo de complexação ${ }^{4}$. Desta forma, para moléculas pequenas é mais fácil formar complexos com $\alpha$ - e $\beta$-CD devido à compatibilidade do volume do substrato e da CD. Já no caso da $\gamma$ $\mathrm{CD}$, se o substrato for muito pequeno o encaixe torna-se desfavorável devido ao tamanho muito maior da cavidade desta CD. É interessante citar que, de forma geral, nenhuma interação fraca individualmente é capaz de levar à interação específica de duas moléculas e tal fato somente pode ocorrer através da cooperação de diversas interações fracas simultâneas ${ }^{7}$. Desta forma, as moléculas interagem umas com as outras à medida que são influenciadas por forças decorrentes das características próprias de cada substância. Ocorre então um fenômeno complexo de interação molecular, uma vez que cada interação corresponde a um conjunto de forças distintas.

As extremidades da cavidade da CD isolada são abertas de tal forma que o substrato pode entrar no anel da CD por ambos os lados. Em solução aquosa, a cavidade levemente apolar é ocupada por moléculas de água que são energeticamente desfavoráveis, dada a natureza da interação polar-apolar e, portanto, podem ser facilmente substituídas por um substrato que seja menos polar que a água. Considera-se que a força motriz para a complexação seja a substituição das moléculas de água de alta entalpia por substratos apropriados ${ }^{2}$.

Em sentido geral, o conceito do tamanho, o qual prediz a alta estabilidade do complexo para o melhor ajuste geométrico e estéreo do substrato e do receptor, pode explicar a tendência geral da termodinâmica da complexação das CDs naturais. Devido aos fatos do diâmetro da cavidade da $\alpha-C D$ ser menor que o da $\beta-C D$ e das forças de van der Waals serem criticamente dependentes da distância entre as moléculas, pode-se esperar que, para um mesmo substrato, as forças induzidas pela complexação da cadeia estendida serão maiores $(-\Delta \mathrm{H})$ para a $\alpha-C D$ que para a $\beta-C D$. Certamente as interações de van der Waals são dependentes tanto do tamanho quanto da forma do substrato incluso ${ }^{7}$.

A formação de complexos de inclusão altera significativamente as características do substrato. Estas alterações incluem modificações na reatividade química do substrato, fixação de substâncias muito voláteis, melhoria na solubilidade de compostos, estabilização de substâncias sensíveis à luz, calor e oxidação, proteção da degradação de substâncias por microorganismos, mascaramento de corantes ou pigmentos e atividade catalítica com substratos. As conseqüências diretas mais importantes da inclusão de um substrato por uma $\mathrm{CD}$ em água são relativas ao aumento da solubilidade do substrato na solução. Ocorrem ainda modificações nas propriedades espectrais do substrato, na reatividade do substrato incluído e ele, inicialmente hidrofóbico, é tornado hidrofílico sob complexação. Da mesma forma, é afetada a volatilidade da molécula incluída, que diminui significativamente.

Em sistema aquoso, a formação do complexo de inclusão com a CD pode ser facilmente detectada através de análise por RMN, dicroísmo circular ou ainda através de espectrofotometria de UVVis e de fluorescência. Nestas últimas técnicas, a molécula incluída apresenta muitas vezes alterações consideráveis de $\lambda_{\text {máx }}$ no espectro de UV-Vis e tem sua fluorescência modificada a partir da inclusão. Ocorrendo a transferência do substrato do ambiente polar aquoso para um microambiente apolar, tal deslocamento pode ser detectado, ainda que em alguns casos não seja possível isolar um complexo de inclusão cristalino bem definido ${ }^{2}$.

Apesar da possibilidade do emprego de diversas técnicas para a investigação do processo de inclusão, apenas análises por RMN podem comprovar a estrutura do complexo formado, a partir da observação de uma alteração sensível dos sinais obtidos tanto para a CD como para o substrato ${ }^{17}$. A modificação nos sinais da CD é consequiência direta das alterações causadas pela associação com o substrato, que altera o microambiente ao redor dos átomos de hidrogênio no interior da cavidade. Da mesma forma, o substrato incluído sofre alteração na leitura dos sinais correspondentes aos átomos que penetram na cavidade da $\mathrm{CD}$, a qual constitui um microambiente diferente daquele em que ele estava originalmente solvatado ${ }^{18}$. $\mathrm{Na}$ indisponibilidade de instrumentos para análise por RMN, diferentes técnicas podem ser utilizadas para estudar a estrutura ou o equilíbrio do complexo de inclusão, as quais incluem, entre outras: técnicas de difusão ${ }^{19}$, calorimetria de varredura diferencial ${ }^{18,20,21}$, análise termogravimétrica ${ }^{18,20,21}$, espectroscopia Raman ${ }^{21}$, fluorescência ${ }^{22}$, espectroscopia de UV-Vis ${ }^{23}$, espectrometria de massa ${ }^{24}$, medidas de condutividade ${ }^{25}$, eletroquímica ${ }^{26}$, dicroísmo circular $^{27}$ e calorimetria ${ }^{28}$. Estas técnicas fornecem indiretamente informações quantitativas e qualitativas sobre os modelos de inclusão e a geometria do complexo obtido.

O ponto de intersecção de um grupo de espectros sobrepostos expressos em função da concentração evidencia a presença de uma mistura de dois estados e é denominado ponto isosbéstico. Em relação à espectroscopia de UV-Vis, a presença de um ponto isosbéstico pode ser considerada uma forte evidência para a formação de complexo de inclusão. Por outro lado, a inexistência de ponto isosbéstico não significa a ausência de complexos de inclusão, uma vez que este constitui somente uma parte da evidência em estudos de sistemas envolvendo complexos, a qual é importante juntamente com outras provas consistentes ${ }^{29}$. Como exemplo, Cramer et al. ${ }^{30}$ estudaram a formação do complexo de inclusão entre $\alpha-C D$ e 4-nitrofenol a partir da conjugação da existência do ponto isosbéstico com a consistência de dados termodinâmicos. 
O complexo de inclusão formado pode ser isolado como uma substância cristalina estável. Dissolvendo-se este complexo, um equilíbrio termodinâmico é estabelecido entre espécies dissociadas e associadas, e este é expresso pela constante de estabilidade do complexo, $K$. O cálculo do valor de $K$ é fundamental para a compreensão dos mecanismos de inclusão macromoleculares, os quais são freqüientemente avaliados através dos métodos espectroscópicos baseados na Equação de Benesi-Hildebrand ${ }^{29,31,32}$. O erro relativo no método de Benesi-Hildebrand ao medir a constante de inclusão do complexo de CD é usualmente alto. Este método é recomendado quando a complexação é modesta (i.e. $K \sim 1000 \mathrm{dm}^{3} \mathrm{~mol}^{-1}$ para a complexação com CD) e com alteração significativa na absorção $0^{33}$. Em outras condições, métodos não-lineares são mais desejáveis ${ }^{33}$.

\section{MECANISMOS RESPONSÁVEIS PELA INCLUSÃO}

Os complexos do tipo receptor-substrato envolvendo CDs e compostos orgânicos têm sido tradicionalmente estudados devido à modelagem simplificada e, ao mesmo tempo, suficientemente sofisticada para a compreensão da natureza das interações não covalentes em solução aquosa $a^{30,34}$. Eles proporcionam informações valiosas relacionadas ao efeito hidrofóbico e às forças de dispersão de London ${ }^{35,36}$.

As contribuições mais relevantes para a termodinâmica da complexação são originárias da entrada da parte hidrofóbica do substrato na cavidade da $\mathrm{CD}$ e da quebra da estrutura da água em torno do substrato orgânico ${ }^{37}$. Uma vez que a cavidade da CD é pronunciadamente lipofílica, a transferência da parte hidrofóbica do substrato, da água para a cavidade da $\mathrm{CD}$, pode ser considerada como um processo típico de efeito hidrofóbico.

O mecanismo completo da formação de complexos de inclusão pode ser dividido em várias etapas ${ }^{7,30,38,39}$, as quais envolvem a dessolvatação do substrato e a dessolvatação interna da $\mathrm{CD}$, mudanças conformacionais do receptor e do substrato, interação receptorsubstrato, uma reorganização do solvente em torno e no interior da cavidade e a relaxação estrutural do complexo. Em relação à solvatação das espécies envolvidas, dois tipos de estrutura da água devem ser inicialmente considerados ${ }^{30}$ : (1) moléculas de água ligadas firmemente a sítios eletricamente carregados ou a grupos com capacidade para formar ligações de hidrogênio e (2) moléculas de água ao redor de grupos hidrofóbicos. A desestruturação dos agregados de água do tipo (1), que envolve o grupo que é inserido no anel da $\mathrm{CD}$, é determinante para a formação do complexo. Quanto mais fortemente ligadas se encontram as moléculas de água, mais vagarosamente serão removidas da esfera de hidratação do substrato ${ }^{30}$.

Tabushi e colaboradores ${ }^{40}$ afirmaram que a estabilização do complexo da CD com o substrato por forças de van der Waals e a remoção da água de solvatação no substrato apolar são fatores responsáveis pela entalpia de inclusão. Quanto maior a estabilização do complexo CD-substrato por forças de van der Waals maior o colapso da estrutura do agregado de água durante o processo de inclusão, e a contribuição relativa destes dois termos compensatórios dita a estabilidade relativa do complexo receptor-substrato para uma série de substratos relacionados. O aumento da entropia devido à quebra da estrutura de solvatação do substrato apolar é substancial e contribui para estabilizar o complexo de inclusão ${ }^{38}$.

Grupos carregados, como amônio e carboxilato, ou grupos hidrofílicos, como hidroxila, amino e carboxila, permanecem expostos à solvatação do meio mesmo após a inclusão em ambiente lipofílico. Uma exceção a esta regra é o grupo hidroxílico aromáti$\mathrm{co}$, que pode penetrar na cavidade da $\mathrm{CD}$, à qual se une por ligações de hidrogênio aos grupos hidroxilados periféricos da $\mathrm{CD}^{41}$. Desta forma, as ligações de hidrogênio podem contribuir para estabilizar o complexo de CDs com tais substratos. As tendências termodinâmicas gerais para reações de complexação de CDs modificadas e naturais são consistentes com o efeito hidrofóbico envolvendo o substrato e a $\mathrm{CD}^{7}$. Existe, obviamente, uma afinidade muito maior entre compostos neutros e a cavidade da CD que entre a cavidade da $\mathrm{CD}$ e as espécies carregadas correspondentes, derivadas do mesmo substrato original $^{16}$. Similarmente, a afinidade aumenta com o aumento da força iônica ou da concentração salina em solução aquosa.

Eftink e colaboradores ${ }^{36}$ estudaram a interação de adamantanocarboxilato (AC) com CDs e verificaram que a ligação de $\mathrm{AC}$ com $\beta$-CD ocorre em uma razão 1:1 e é orientada quase completamente por uma variação negativa da entalpia. Este é um exemplo do que Jencks definiu como sendo uma "interação hidrofóbica não clássica" $^{42}$, considerando-se que seria de se esperar que a associação destas moléculas fosse dirigida hidrofobicamente e por fatores entrópicos. Os estudos efetuados da dependência do solvente permitiram aos mesmos autores concluir que o efeito hidrofóbico responde por aproximadamente $30 \%$ da energia livre de ligação do AC com $\beta-C D^{36}$, porém esta contribuição é eclipsada por uma forte interação de van der Waals, resultante do ajuste bastante adequado do substrato à cavidade da $\beta$-CD. Por outro lado, a ligação envolvendo $\mathrm{AC}$ e $\gamma-\mathrm{CD}$ é caracterizada por uma pequena variação positiva de entalpia e uma grande variação positiva da entropia, o que corresponde ao padrão de um efeito hidrofóbico clássico ${ }^{36,43}$. As interações receptor-substrato de sildenafil com CDs foram investigadas com o uso de diferentes técnicas ${ }^{44}$, tendo sido observado que o caráter hidrofóbico do substrato é responsável por $39 \%$ da força motriz para a estabilidade do complexo formado, enquanto outros fatores, que incluem interações específicas, contribuem com $-7,9 \mathrm{~kJ} / \mathrm{mol}$. A formação do complexo envolvendo sildenafil e $\beta$-CD é dirigida principalmente pelo fator entálpico, sendo que a força motriz dominante para a complexação é do tipo de van der Waals com uma contribuição eletrostática muito pequena $^{44}$. Em um trabalho bastante recente, Viernstein e colaboradores $^{45}$ demonstraram que, dependendo da estrutura da CD empregada e da natureza do substrato que irá se ligar a ela, mecanismos de interação completamente diferentes são observados, podendo estes processos apresentar compensação entálpica/entrópica ou serem controlados entropicamente. Demonstraram ainda que processos de protonação e desprotonação do substrato influenciam significativamente a reação de inclusão ${ }^{45}$. Buvári-Barcza e colaboradores ${ }^{46}$ estudaram a interação de ácidos dicarboxílicos alifáticos com CDs. Foi observado um aumento significativo e relativamente inesperado das constantes de inclusão para ácidos dicarboxílicos monoprotonados (HA') apresentando ligação de hidrogênio intramolecular. Embora as ligações de hidrogênio entre o substrato e os grupos hidroxilados presentes na $\mathrm{CD}$ sejam responsáveis pelo aumento da estabilidade nos complexos de inclusão ${ }^{47}$, foi verificado que a maior inclusão das espécies HA ocorre pelo fato de que o substrato, por ligação de hidrogênio intramolecular, fica mais compacto, ajustando-se desta maneira melhor à cavidade da $\mathrm{CD}^{46}$. Assim, a partir dos exemplos que foram aqui descritos, pode-se concluir que a natureza termodinâmica dos processos de formação de complexos de inclusão envolvendo substratos orgânicos e CDs depende do meio e de aspectos estruturais ligados às espécies envolvidas.

\section{POLARIDADE DAS CICLODEXTRINAS}

É largamente conhecido que as CDs apresentam uma parte externa polar, enquanto a parte interna é lipofílica ${ }^{7,48}$. Estudos têm sido feitos por muitos autores na busca de estimativas acerca da micropolaridade das $\mathrm{CDs}^{48}$, sendo estas investigações importantes para o entendimento de uma série de questões que envolvem desde a natureza das interações receptor-substrato até a solubilidade de CDs em diferentes meios. 
As investigações físico-químicas da polaridade do meio são comumente realizadas com a ajuda de sondas solvatocrômicas ${ }^{49-54}$, as quais denotam, por alteração na polaridade do meio, mudanças na posição da banda na região visível do espectro e algumas vezes também na posição da banda de emissão de fluorescência. Um exemplo importante é proporcionado pelo corante 2,6-difenil-4(2,4,6-trifenil-1-piridínio)-1-fenolato (1), que é um dos corantes solvatocrômicos mais comumente empregados em solução ${ }^{49}$. Um outro exemplo bastante conhecido é o corante 4-[(1-metil-4(1H)piridinilideno)-etilideno]-2,5-cicloexadien-1-ona (2), mais conhecido como merocianina de Brooker ${ }^{50}$. Estes corantes têm sido usados em anos recentes em diversos estudos, por exemplo, de solvatocromismo $^{49,50}$, halocromismo ${ }^{51}$, misturas de solventes ${ }^{52}$, líquidos iônicos ${ }^{53}$ e micro-heterogeneidade em solução $0^{54}$.
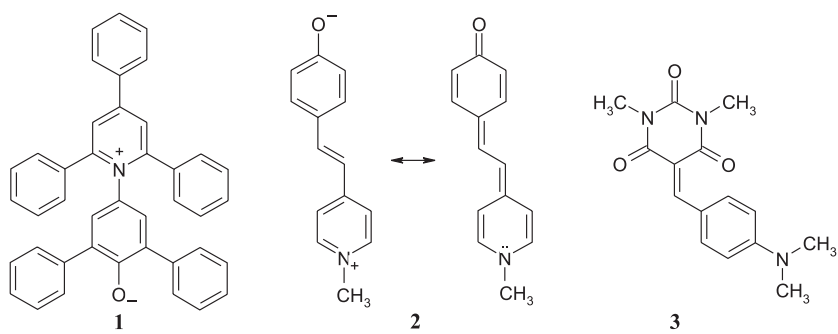

Um estudo do efeito da adição de metil- $\beta$-CD sobre as bandas solvatocrômicas de $\mathbf{1}$ e $\mathbf{2}$, usando-se a técnica de UV-Vis em diversos solventes doadores e aceitadores de ligações de hidrogênio, mostrou que os corantes tomam parte em interações específicas fortes, como ligações de hidrogênio e efeito hidrofóbico ${ }^{55}$. Em água, os dados espectroscópicos envolvendo os corantes e a CD apontaram para o fato de que deslocamentos batocrômicos ocorrem em suas bandas solvatocrômicas quando a CD é adicionada, o que sugere a inclusão dos corantes na cavidade da CD e fornece informações sobre a natureza hidrofóbica desta cavidade ${ }^{55}$. Recentemente, Rezende e colaboradores ${ }^{56}$ estudaram a complexação da merocianina 3, derivada do ácido barbitúrico, com $\beta-\mathrm{CD}$ em água usando a técnica de UV-Vis. Os resultados obtidos indicaram que o microambiente aquoso do corante é gradualmente substituído por outro de menor polaridade à medida que a $\mathrm{CD}$ é adicionada. Em outro estudo recente de Rezende e colaboradores ${ }^{57}$, envolvendo a interação de piridiniofenolatos solvatocrômicos com CDs, foram observados deslocamentos batocrômicos para as bandas solvatocrômicas dos corantes em água pela adição de concentrações crescentes de CDs.

Embora o uso de corantes para explorar a micropolaridade de CDs demonstre a natureza lipofílica da sua parte interior, é difícil fazer uma analogia entre os dados obtidos pelas sondas na presença de CDs e aqueles obtidos com as sondas em solventes puros e solventes misturados, conforme pretenderam alguns autores ${ }^{48,58}$. Isto decorre do fato dos compostos estudados apresentarem diferentes estruturas, o que faz com que eles se localizem em diferentes regiões no interior das CDs, levando-os a relatarem micropolaridades diferentes. Assim, estudos adicionais se fazem necessários com novas séries de corantes especialmente planejados para atuarem como "réguas moleculares" 59 capazes de medir a micropolaridade em diferentes profundidades das CDs.

\section{CICLODEXTRINAS EM PROCESSOS SUPRAMOLECULARES}

Em sua vertente mais clássica, a química supramolecular foi definida como a química além da molécula, tendo por fundamento a utilização de interações não covalentes para a formação de com- plexos do tipo receptor-substrato, capazes de desempenhar funções de reconhecimento molecular, de transformação e de transporte $^{60}$. O desenvolvimento das pesquisas em áreas tais como de automontagem, de auto-organização e de sistemas supramoleculares programados tornaram possível uma nova definição da química supramolecular como uma ciência da informação $o^{61}$. As CDs constituem blocos de construção bastante versáteis para serem empregados em processos supramoleculares de uma maneira geral, o que ajuda a explicar o porquê do seu estudo representar atualmente um campo de grande importância para a química supramolecular.

Um primeiro aspecto que vem sendo estudado há bastante tempo refere-se ao uso das CDs como receptores para o reconhecimento molecular de diferentes tipos de substratos. A importância destes estudos, ilustrada com trabalhos recentes nesta área, já foi mencionada nas seções anteriores, mas merece ainda ser ressaltado que o uso de CDs como unidades de reconhecimento molecular em associação com unidades de sinalização fluorescentes ou que absorvam na região visível do espectro tem dado contribuições importantes no campo da química dos sensores colorimétricos e fluorescentes para diferentes analitos ${ }^{62}$. Os estudos envolvendo CDs são bastante importantes para a compreensão dos mecanismos de ação enzimática, o que tem motivado muitos grupos de pesquisa para o desenvolvimento de inúmeros modelos enzimáticos e de enzimas artificiais que trazem CDs em sua arquitetura ${ }^{63}$. Estes sistemas modelos aproveitam a habilidade das CDs de serem solúveis em água, de apresentarem uma cavidade lipofílica adequada para reconhecer substratos e, ainda, a possibilidade de serem funcionalizadas com grupos hábeis para, atuando de forma integrada, aumentar a especificidade do reconhecimento do substrato e exercer função catalítica pela sua proximidade com o centro reativo. Desta forma, o conhecimento da estrutura do sítio ativo de muitas enzimas auxilia na montagem destes sistemas e tem inspirado os químicos na montagem de enzimas artificiais capazes de catalisar reações que as enzimas naturais não conseguem realizar ${ }^{63}$. Da mesma forma que as CDs catalisam diferentes processos podem, ainda, ser responsáveis pela inibição de muitas reações, o que é de interesse quando o que se deseja é proteger o substrato dos diferentes agentes no meio em que ele se encontra. Um exemplo foi proporcionado recentemente por um trabalho em que se demonstra que a formação de um complexo de inclusão de uma $\gamma$-CD com ampicilina reduz a velocidade de hidrólise do antibiótico na presença de $\beta$ lactamase ${ }^{17}$. Estudos desta natureza apresentam importância considerando-se que $\beta$-lactamases são produzidas por bactérias, com o intuito de inibir a atividade do antibiótico. Um outro aspecto importante a ser evidenciado é a capacidade antioxidante que $\alpha$-, $\beta$ - e $\gamma$-CD apresentam ${ }^{64}$. No campo dos estudos relacionados com o transporte, as CDs vêm sendo empregadas como catalisadores de transferência de fase ${ }^{65}$, como dopantes em membranas poliméricas para o transporte de metais ${ }^{66}$, na montagem de canais iônicos ${ }^{67} \mathrm{e}$ em processos de extração de hidrocarbonetos ${ }^{68}$.

$\mathrm{O}$ complexo $\mathrm{F}_{0} \mathrm{~F}_{1}$-ATPase pode ser considerado uma máquina molecular de alta eficiência que acopla a rotação de uma roda em um eixo com a geração de trifosfato de adenosina (ATP), a moeda corrente de energia em nível celular ${ }^{69}$. Este sistema, considerado como um protótipo em escala nanométrica de um motor macroscópico, é visto como fonte de inspiração para muitos grupos de pesquisa no desenvolvimento de máquinas moleculares apresentando dispositivos na forma de rotaxanos e de catenanos ${ }^{70}$. Para o planejamento destas estruturas supramoleculares, é necessário o uso de componentes cíclicos que possam ser atravessados por eixos moleculares e que apresentem potencial para executar funções tais como a rotação unidirecional e a transposição. Assim, as CDs, devido a sua natureza cíclica, têm sido empregadas como compo- 
nentes cíclicos na construção destas arquiteturas supramoleculares ${ }^{70}$.

A capacidade das CDs para formarem complexos com substratos lipofílicos foi aproveitada recentemente para a síntese de polímeros supramoleculares a partir de unidades monoméricas representadas por cinamamida ligada às posições 3 ou 6 de $\alpha$ - ou $\beta-\mathrm{CDs}^{71}$. As interações supramoleculares de CDs com materiais poliméricos merecem atenção especial, pois parecem ser responsáveis por efeitos inusitados, conforme mostrado recentemente por Schmitz e Ritter ${ }^{72}$ para um polímero preparado à base de polimetacrilamida, que se torna solúvel em água na presença de $\beta$-CD em baixa temperatura. Com o aumento da temperatura, o polímero torna-se insolúvel, voltando a solubilizar por resfriamento na mesma faixa de temperatura, o que caracteriza um processo de complexação-descomplexação reversível ${ }^{72}$. Em outro trabalho foi explorada uma nanoestruturação polimérica com o uso de $\mathrm{CDs}^{73}$. A capacidade estruturadora das CDs foi ainda estudada recentemente na qualidade de 'chaperones' artificiais para a renaturação de uma proteína ${ }^{74}$. A associação das CDs à química dos polímeros tem permitido uma ampla faixa de aplicações que envolvem, por exemplo, o desenvolvimento de um sistema para a liberação de insulina com aplicação nasal ${ }^{75}$, o uso de nanoesferas em sistemas de floculação/ sorção $0^{76}$, o estudo da pervaporação de misturas de benzeno com cicloexano $^{77}$ e o desenvolvimento de adutos supramoleculares paramagnéticos para aplicações como agentes de contraste em imagem por ressonância magnética ${ }^{78}$.

Merece destaque ainda o uso de CDs para o desenvolvimento de receptores moldados especialmente para determinados substratos pelo uso da estratégia da impressão molecular ("molecular imprinting"). Neste caso, faz-se em uma primeira etapa a complexação do substrato-molde com a $\mathrm{CD}$ e a seguir é realizada uma reticulação na presença do complexo, com o uso de um monômero apropriado. Após a remoção do molde, a cavidade do novo receptor pode ser explorada para o reconhecimento do substrato ${ }^{79}$. Além da técnica da impressão molecular, a interação de sílicas modificadas com CDs foi investigada para a obtenção de centros de adsorção para moléculas bioativas ${ }^{80}$, da mesma forma como o metoxicinamato de octila, um agente protetor solar, pôde ser incorporado nas cavidades de uma $\beta$-CD especialmente funcionalizada para se ligar covalentemente a uma fibra celulósica ${ }^{81}$.

\section{CICLODEXTRINAS EM QUÍMICA AMBIENTAL}

As preocupações crescentes nos últimos anos no que concerne ao respeito ao meio ambiente levaram a comunidade científica ao desenvolvimento de toda uma área de pesquisa que recebe a denominação de química verde ${ }^{82}$. Neste sentido, as CDs têm sido alvo de numerosos estudos, sendo utilizadas com sucesso como moléculas receptoras eficientes na remoção de poluentes lançados ao solo. Elas podem transferir continuamente os contaminantes insolúveis da superfície do solo para a fase aquosa pela formação de complexos solúveis em água. Na fase aquosa, os microorganismos podem degradar os contaminantes de forma muito mais fácil e rápida, isso porque estas moléculas se tornam disponíveis para o sistema microbial e ainda, em particular, pela capacidade que as CDs possuem em reduzir a toxicidade da molécula inclusa ${ }^{83}$. Hanna e colaboradores $^{84}$ têm utilizado $\beta$-CDs em água para o desenvolvimento de um método inovador para a despoluição de solos em áreas industriais, contaminados com hidrocarbonetos policíclicos aromáticos (HPAs). Os estudos mostraram que o uso de CDs em água aumentou a capacidade de extração de HPAs em cerca de 200 vezes em comparação com a água pura ${ }^{84}$.

Um outro aspecto das aplicações das CDs que vem ganhando destaque atualmente envolve seu uso no desenvolvimento de metodologias para a remoção do caráter tóxico (detoxificação) de muitos compostos potencialmente agressivos aos sistemas vivos. Os hidrocarbonetos clorados são compostos de alta toxicidade, sendo que os que são voláteis causam efeitos deletérios sobre a camada de ozônio, enquanto os compostos bifenílicos policlorados (PCBs) são reconhecidos pelo seu impacto social sobre a saúde humana ${ }^{85}$. Estudos vêm sendo feitos atualmente com o objetivo de se aplicar CDs no desenvolvimento de metodologias que visam a degradação destes compostos. Ponchel e colaboradores desenvolveram um processo ecoeficiente de decomposição do tetracloreto de carbono em metano e cloreto, com o uso de solução aquosa básica em condições de temperatura ambiente ${ }^{86}$. Nesta estratégia, as CDs são usadas para aprisionar o poluente orgânico em água a fim de que ele possa ser degradado por um catalisador heterogêneo contendo paládio. Merece ainda ser mencionado o uso de $\beta$-CDs no desenvolvimento de biorreatores para a biodegradação de $\mathrm{PCBs}^{87}$. Em outra vertente bastante interessante, uma estratégia para a detoxificação de gases dos nervos foi estudada, envolvendo o uso de nanofibras funcionalizadas com uma $\beta$-CD ligada ao ácido $o$-iodosobenzóico ${ }^{88}$. O catalisador foi empregado para a descontaminação do paraoxon, um agente estimulante dos nervos. Em outro trabalho recente foi proposta uma metodologia para a detoxificação de mercúrio em água, baseada na inclusão de mercúrio em $\alpha-\mathrm{CD}^{89}$.

As CDs formam complexos com uma variedade de compostos utilizados na área agrícola, tais como herbicidas ${ }^{90}$, fungicidas ${ }^{91}$, inseticidas ${ }^{92}$, feromônios ${ }^{93}$ e reguladores de crescimento $^{94}$, sendo estes trabalhos de interesse especial devido à formação destes complexos de inclusão geralmente resultar em melhorias nas propriedades físico-químicas dos agroquímicos, tais como o aumento da solubilidade e da biodisponibilidade, o aumento da estabilidade no caso de compostos instáveis ou fotodegradáveis, a redução do aroma desagradável e a redução da toxicidade em sistemas vivos ${ }^{83,95}$. As aplicações potenciais das CDs nesta área atendem ainda a outras questões importantes, tais como a liberação controlada dos substratos, biodegradabilidade da molécula receptora, possibilidade de efeitos catalíticos sobre a degradação de pesticidas e mesmo a solubilidade dos complexos formados em água, o que deve permitir a fácil remoção dos agroquímicos no solo.

\section{APLICAÇÕES EM QUÍMICA ANALÍTICA}

Conforme já apresentado ao longo deste texto, as CDs podem identificar seletivamente diversas espécies químicas e, portanto, diversos métodos analíticos podem ser desenvolvidos baseados no emprego das mesmas. Durante o último século, muitos fármacos quirais têm sido desenvolvidos e usados na forma de racematos. Se já não bastasse o fato de os enantiômeros de moléculas quirais diferirem nas atividades farmacológicas, ainda um destes pode ser responsável por efeitos tóxicos indesejáveis ${ }^{96}$. Atualmente, a tendência geral consiste no desenvolvimento de novos fármacos quirais na forma de enantiômeros puros. Nesta nova situação, moléculas capazes de fazer este reconhecimento quiral, tais como as CDs, tornam-se receptores altamente promissores e desejáveis. A quiralidade e o reconhecimento quiral são características importantes da natureza e de essencial importância para a compreensão de numerosos processos químicos e biológicos ${ }^{28}$. Muitas técnicas que são utilizadas para a resolução quiral, tais como cromatografia líquida de alta resolução (HPLC), eletroforese capilar (EC), cromatografia gasosa (CG), cromatografia em camada delgada e eletrocromatografia capilar (ECC), têm utilizado as CDs como espécies capazes de diferenciar enantiômeros em racematos ${ }^{97}$.

A utilização de CDs como fase estacionária em coluna quiral em CG foi primeiramente descrita por Koening, em 1988, utilizando CDs pentiladas ${ }^{12}$. Desde então, as CDs vêm sendo utilizadas 
para a identificação de diferentes compostos. Em 1965, Solms e Egli foram os primeiros a descreverem trabalhos utilizando CDs e sua seletividade na determinação de vários compostos a partir da resina de CD epicloroidrina como fase estacionária em HPLC ${ }^{12}$. Em 1985, a utilização da fase estacionária contendo nitrogênio e enxofre ligados a CDs foi desenvolvida por Armstrong, tornandose comercialmente viável ${ }^{12}$.

Dentre os métodos cromatográficos, a HPLC é a técnica mais utilizada para separação de enantiômeros, podendo ser realizada por métodos diretos ou indiretos ${ }^{98}$. No entanto, os últimos anos foram marcados pela implementação de outra técnica instrumental de separação importante, a EC ${ }^{98}$, pela sua versatilidade e simplicidade instrumental ${ }^{99}$. Os métodos e as pesquisas em EC continuam sendo a maior área de separação quiral analítica com o uso de CDs como seletores quirais. Isto se deve à solubilidade e estabilidade das CDs em solução aquosa, custo e excelente seletividade oferecida pelas CDs naturais e modificadas ${ }^{97}$. Até o momento, as CDs permanecem como o mais importante grupo de seletores quirais em EC, pela sua popularidade e diversidade ${ }^{100}$. É possível observar na técnica de EC, como um exemplo, a detecção de antiinflamatórios derivados do sulindac presentes no plasma sangüíneo, medicamentos estes usados para tratamento de artrite reumática e osteoartrite. Em função da baixa resolução dos antiinflamatórios por EC, surgiu a necessidade da adição de uma espécie que alterasse a mobilidade eletroforética do analito e melhorasse sua resolução. Os testes realizados utilizaram $\alpha-\mathrm{CD}, \beta-\mathrm{CD}, \gamma-\mathrm{CD}$, hidroxipropil- $\beta$-CD (HP- $\beta-\mathrm{CD})$ e dimetil$\beta-\mathrm{CD}$ e foi observado que a dimetil- $\beta$-CD apresentou melhor resolução, em função da elevada interação da cavidade lipofílica da CD com o analito lipofílico ${ }^{101}$. O uso de CDs como seletores quirais capazes de alterar a mobilidade eletroforética do analito caracteriza um método altamente específico, preciso e seguro, garantindo estabilidade da solução ${ }^{101}$. A associação do método de UV-Vis com o método de EC permite um melhor controle do produto final da indústria farmacêutica para diferentes medicamentos ${ }^{101}$.

As CDs têm favorecido a seletividade quiral com compostos cíclicos, principalmente aromáticos, mas um grande número de enantiômeros alifáticos também é separado por elas. As ligações de hidrogênio servem como interação fundamental em várias resoluções enantioméricas. A regra geral é que a posição $\alpha$ do centro assimétrico do grupo que estabelece ligação com as CDs é preferida, mas grupos funcionais localizados no ligante também têm sido separados por elas. Há evidências de que grupos polares ligados a CDs modificadas (tais como grupamentos acila e hidroxipropila) oferecem melhor separação quiral que grupos apolares ligados a elas (tais como grupamentos pentila e metila), quando se referem a analitos polares em $\mathrm{CG}^{102}$. O fato das CDs possuírem o carbono 6 ligado a um grupo hidroxila, com rotação livre, capaz de bloquear parcialmente a base inferior da $\mathrm{CD}$, e a presença dos carbonos 2 e 3 secundários localizados na base superior da $\mathrm{CD}$, favorece a formação de complexos com muitos racematos. Assim, a presença de unidades de glicopiranoses estereoespecíficas restringe a rotação dos grupos hidroxilas secundários, que são, supostamente, os responsáveis pela capacidade de reconhecimento quiral das $\mathrm{CDs}^{98}$.

$\mathrm{O}$ reconhecimento de analitos por meio de interação com o receptor é uma técnica promissora na área da fotoquímica, especialmente empregando complexos supramoleculares que têm se mostrado sensíveis ao reconhecimento de espécies. Estas estruturas supramoleculares, com o uso das CDs como receptores, são promissoras na detecção das mais variadas espécies químicas ${ }^{103,104}$. $\mathrm{O}$ uso de complexos de inclusão com CDs em combinação com técnicas de luminescência no estudo e determinação de compostos e elementos apresentando interesse ambiental foi revisado recentemente ${ }^{105}$.
Considerando-se que a discriminação quiral é muito importante no desenvolvimento de fármacos na indústria farmacêutica e que a interação do fármaco com o receptor é altamente estereosseletiva, as técnicas eletroquímicas oferecem vantagens na detecção de espécies sobre outros métodos pelo baixo custo, rapidez na análise, alta seletividade e simplicidade ${ }^{106}$. Stefan et al. ${ }^{106}$ têm estudado o uso de um sensor potenciométrico baseado na 2-hidróxi-3-trimetilamoniopropil- $\beta$-CD para análise do $S$-perindopril ${ }^{106}$, enquanto as CDs naturais foram usadas por Ozoemena e colaboradores ${ }^{106}$ para a determinação do $S$-perindopril em formulações farmacêuticas. Estes testes preliminares com eletrodos geraram bons resultados.

\section{CICLODEXTRINAS EM PROCESSOS INDUSTRIAIS}

Até a década de 70, embora se soubesse da capacidade das CDs para formarem complexos de inclusão, as iniciativas para aplicá-las industrialmente foram muito tímidas, basicamente por três motivos: eram disponíveis somente em quantidades pequenas a preços nada acessíveis; os estudos toxicológicos incompletos alertavam para uma toxicidade adversa e, o conhecimento alcançado sobre as CDs não era ainda suficientemente amplo para se vislumbrar seu aproveitamento pela indústria. No entanto, a partir das décadas de 70 e 80 , como conseqüência da intensa pesquisa realizada neste campo, alcançou-se êxito na produção de CDs e seus derivados em escala industrial e ensaios confiáveis dirimiram dúvidas sobre a sua toxicidade, o que possibilitou a aplicação em diversos campos da indústria, tais como em produtos farmacêuticos, alimentícios, cosméticos, na área têxtil e em biotecnologia ${ }^{107}$.

Um dos aspectos que seguramente reveste as CDs de grande importância para serem potencialmente aplicadas em processos industriais refere-se à melhoria da solubilidade dos substratos em água. $\mathrm{O}$ controle da solubilidade pode ser efetuado via seleção de uma CD adequada, sendo que a modificação dos grupos hidroxílicos na face externa da CD pode alterar pronunciadamente sua própria solubilidade $^{18}$. O praziquantel (PZQ), um anti-helmíntico eficiente, foi encapsulado à $\beta-C D$, tendo sido o complexo analisado com o uso de RMN de ${ }^{1} \mathrm{H}$ bidimensional, o qual revelou uma estequiometria 1:1 $\beta$-CD/PZQ ${ }^{108}$. O diagrama de fase-solubilidade revelou um aumento em cinco vezes na solubilidade em água do PZQ correspondente ao aumento na concentração de $\beta-\mathrm{CD}$, o que elevou sua atividade farmacológica ${ }^{108}$. Uzqueda e colaboradores ${ }^{109}$ analisaram as interações do antifúngico naftifina com $\alpha-\mathrm{CD}, \beta-\mathrm{CD}$, metil- $\beta-\mathrm{CD}, \mathrm{HP}-\beta-\mathrm{CD}$ e $\gamma-\mathrm{CD}$, tendo observado um aumento na solubilidade do fármaco em $2,5,9$ e 21 vezes para $\gamma-C D, \beta-C D$, HP- $\beta-C D$ e metil- $\beta-C D$, respectivamente. Estes resultados mostraram-se adequados para uma possível aplicação farmacêutica. Valsartan, um fármaco anti-hipertensivo, foi complexado com HP- $\beta$-CD e os estudos efetuados com o complexo demonstraram uma melhoria na solubilidade, taxa de dissolução e estabilidade do fármaco ${ }^{110}$.

As nanopartículas têm atraído a atenção de pesquisadores por apresentarem potencialidades terapêuticas e estabilidade nos fluidos biológicos. As nanopartículas incluem nanoesferas e nanocápsulas, as quais diferem entre si em relação à composição e organização estrutural ${ }^{111}$. O uso potencial de nanopartículas preparadas com CDs anfifílicas como carreadores de fármacos tem sido explorado com sucesso, melhorando as características físico-químicas dos fármacos ${ }^{112}$. Nanoesferas preparadas com $\beta-C D$ anfifílica contendo metronidazol apresentaram alta eficiência de encapsulamento e com tamanho de partículas apropriado para administração intravenosa ${ }^{113}$.

O sabor amargo de fármacos, alimentos ou de qualquer outra substância dissolvida em solução aquosa ou na saliva, pode ser reduzido ou totalmente eliminado se o componente amargo formar um 
complexo de inclusão com uma CD apropriada ${ }^{114}$. Em geral, as substâncias que apresentam ausência de sabor são moléculas insolúveis em água. Todavia, muitos fármacos são dificilmente toleráveis, apresentando sabor amargo em mínimas concentrações. Coube a Freudenberg e colaboradores descrever pela primeira vez a alteração do sabor desagradável de uma substância por complexação com $\mathrm{CD}^{115}$. Os ácidos graxos insaturados, como óleos de peixe e óleos vegetais, sofrem oxidação facilmente resultando em sabor e odor desagradáveis, tendo sido demonstrado que a sua oxidação pode ser evitada pela complexação a $\mathrm{CDs}^{18}$. A complexação em $\beta-\mathrm{CD}$, ligada à quitosana, de substratos originados de extratos naturais e da cafeína mostrou eficiência na atenuação do seu sabor desagradável ${ }^{116}$.

A preparação de cosméticos é outra área na qual se utiliza a complexação de moléculas com CDs, como por exemplo, na diminuição da volatilidade de perfumes. A estabilização, o controle do odor e o aperfeiçoamento do processo envolvendo a conversão de um ingrediente líquido para a forma sólida são os principais benefícios dessas macromoléculas neste setor ${ }^{117}$. A complexação de triclosan com CDs aumentou a disponibilidade do antimicrobiano na formulação de uma pasta dental ${ }^{118}$. A interação de aromas com CDs é ainda de especial interesse para a indústria de alimentos ${ }^{119} \mathrm{e}$ no desenvolvimento de produtos têxteis aromoterápicos ${ }^{120}$.

\section{PERSPECTIVAS}

Os estudos envolvendo as CDs têm conhecido um crescimento vertiginoso nos últimos anos ${ }^{121}$ e elas têm se tornado populares em diferentes campos do conhecimento e de aplicação tecnológica. É razoável considerar que, com a evolução de campos recentes do conhecimento, tais como a química supramolecular, a nanotecnologia e a química verde, as CDs possam, pelo seu baixo custo, grande disponibilidade e baixa toxicidade, serem empregadas como blocos moleculares importantes para atuar como receptores eficientes e, desta forma, auxiliar na solução dos diferentes tipos de problemas que se descortinam. Assim, as CDs vêm representando um papel de destaque em inúmeras áreas, tais como na montagem de sistemas de liberação controlada de fármacos ${ }^{122}$, em terapia imunomodulatória ${ }^{123}$ e em processos de encapsulação de gases apresentando importância comercial, ambiental e biológica ${ }^{124}$. A interação do DNA com $\beta$-CDs devidamente acomodadas em polieletrólitos oferece a possibilidade de liberação controlada de diferentes fragmentos de DNA, abrindo caminho para numerosas aplicações potenciais ${ }^{125}$. No campo da nanotecnologia, os estudos dos nanoagregados de CDs são bastante promissores. Nano-partículas injetáveis podem ser desenvolvidas para serem utilizadas como nanocarreadores inteligentes, hábeis para liberar fármacos em tecidos específicos e em terapia fotodinâmica ${ }^{126}$. Merece ainda destaque o uso de CDs no desenvolvimento de quadros de impressão supramoleculares, que são de interesse para a área de nanofabricação ${ }^{127}$. Os exemplos recentes que ilustram o texto apresentado não esgotam a lista de possíveis aplicações para as CDs. Ao pensar nelas, torna-se impossível deixar de evocar o célebre princípio formulado por Paul Ehrlich em sua forma proverbial: corpora non agunt nisi fixata $^{128}$. É precisamente na sua capacidade de ligação aos substratos que reside sua força para transformá-los e amplificar a sua ação!

\section{AGRADECIMENTOS}

\section{À FURB, à Capes e ao CNPq pelo apoio financeiro.}

\section{REFERÊNCIAS}

1. D'Souza, V. T.; Lipkowitz, K. B.; Chem. Rev. 1998, 98, 1741.

2. Szejtli, J.; Chem. Rev. 1998, 98, 1743.

3. Chung, W.-S.; Turro, N. J.; Silver, J.; Lenoble, W. J.; J. Am. Chem. Soc. 1990, 112, 1202.
4. Harata, K.; Chem. Rev. 1998, 98, 1803.

5. Schmid, G. Em Comprehensive Supramolecular Chemistry; Atwood, J.; Davies, E. D.; MacNicol, D. D.; Vögtle, F., eds.; Pergamon: Oxford, 1996, p. 41-56; Biwer, A.; Antranikian, G.; Heinzle, E.; Appl. Microbiol. Biotechnol. 2002, 59, 609; Qi, Q. S.; Zimmermann, W.; Appl. Microbiol. Biotechnol. 2005, 66, 475; Wang, Z.; Qi, Q.; Wang, P. G.; Appl. Environ. Microbiol. 2006, 72, 1873; Pishtiyski, I.; Zhekova, B.; World J. Microbiol. Biotechnol. 2006, 22, 109.

6. Gattuso, G.; Nepogodiev, A.; Stoddart, J. F.; Chem. Rev. 1998, 98, 1919.

7. Rekharsky, M. V.; Inoue, Y.; Chem. Rev. 1998, 98, 1875.

8. Khan, A. R.; Forgo, P.; Stine, K. J.; D’Souza, V. T.; Chem. Rev. 1998, 98 , 1977.

9. Ver por exemplo: Jicsinsky, L.; Fenyvesi, E. Em Comprehensive Supramolecular Chemistry; Atwood, J. L.; Davies, J. E.; MacNicol, D. D.; Vögtle, F., eds.; Pergamon: Oxford, 1996, vol. 3; Jensen, K. J.; Brask, J.; Biopolymers 2005, 80, 747; Benmerad, B.; Clair, P.; Armspach, D.; Matt, D.; Balegroune, F.; Toupet, L.; Chem. Commun. 2006, 2678; Yamanoi, T.; Kobayashi, N.; Takahashi, K.; Hattori, K.; Lett. Drug Des. Discovery 2006, 3, 188; Murayama, T.; Tanabe, T.; Ikeda, H.; Ueno, A.; Bioorg. Med. Chem. 2006, 14, 3691; Bistri, O.; Sinay, P.; Sollogoub, M.; Chem. Commun. 2006, 1112; Kraus, T.; Budesinsky, M.; Zavada, J.; Tetrahedron Lett. 2006, 47, 679. 10. Villiers, A.; Compt. Rend. 1891, 112, 536.

11. Schardinger, F.; Z. Unters. Nahr. u. Genussm. 1903, 6, 865; Schardinger, F.; Zentralbl. Bakteriol. Parasitenk. Abt 2 1911, 29, 188.

12. Li, S.; Purdy, W. C.; Chem. Rev. 1992, 92, 1457.

13. Freudenberg, K.; Blomquist, G.; Ewald, L.; Soff, K.; Ber. Dtsch. Chem. Ges. 1936, 69, 1258.

14. Saenger, W. R.; Jacob, J.; Gessler, K.; Steiner, T.; Hoffmann, D.; Sanbe, H.; Koizumi, K.; Smith, S. M.; Takaha, T.; Chem. Rev. 1998, 98, 1787.

15. Takahashi, K.; Chem. Rev. 1998, 98, 2013.

16. Rekharsky, M. V.; Goldberg, R. N.; Schwarz, F. P.; Tewari, Y. B.; Ross, P. D.; Yamashoji, Y.; Inoue, Y.; J. Am. Chem. Soc. 1995, 117, 8830.

17. Ver, por exemplo: Schneider, H.-J.; Hacket, F.; Rüdiger, V.; Ikeda, H.; Chem. Rev. 1998, 98, 1755; Pons, M.; Millet, O.; Prog. Nucl. Magn. Reson. Spectrosc. 2001, 38, 267; Ramstad, T.; Hadden, C. E.; Martin, G. E.; Speaker, S. M.; Teagarden, D. L.; Thamann, T. J.; Int. J. Pharm. 2005, 296, 55; Maffeo, D.; Leondiadis, L.; Mavridis, I. M.; Yannakopoulou, K.; Org. Biomol. Chem. 2006, 4, 1297; Hao, Y. Q.; Wu, Y. Q.; Liu, J. Q.; Lao, G. M.; Yang, G. D.; J. Inclusion Phenom. Macrocyclic Chem. 2006, 54, 171.

18. Hedges, A. R.; Chem. Rev. 1998, 98, 2035.

19. Loh, W.; Quim. Nova 1997, 20, 541; Lino, A. C. S.; Loh, W.; J. Inclusion Phenom. Macrocyclic Chem. 2000, 36, 267; de Azevedo, M. B. M.; Alderete, J. B.; Lino, A. C. S.; Loh, W.; Faljoni-Alario, A.; Duran, N.; J. Inclusion Phenom. Macrocyclic Chem. 2000, 37, 67; Cameron, K. S.; Fielding, L.; J. Org. Chem. 2001, 66, 6891.

20. Meier, M. M.; Luiz, M. T. B.; Szpoganicz, B.; Soldi, V.; Thermochim. Acta 2001, 375, 153; Giordano, F.; Novák, C.; Moyano, J. R.; Thermochim. Acta 2001, 380, 123; Fernandes, L. P.; Éhen, Z.; Moura, T. F.; Novák, C.; Sztatisz, J.; J. Therm. Anal. Calorim. 2004, 78, 557; Fernandes, J. A.; Lima, S.; Braga, S. S.; Ribeiro-Claro, P.; Rodriguez-Borges, J. E.; Teixeira, C.; Pillinger, M.; Teixeira-Dias, J. J. C.; Gonçalves, I. S.; J. Organomet. Chem. 2005, 690, 4801; Novák, C.; Éhen, Z.; Fodor, M.; Jicsinszky, L.; Orgoványi, J.; J. Therm. Anal. Calorim. 2006, 84, 693.

21. Ribeiro-Claro, P. J. A.; da Costa, A. M. A.; Vueba, M. L.; Pina, M. E.; Amado, A. M.; J. Raman Spectrosc. 2006, 37, 472.

22. Catena, G. C.; Bright, F. V.; Anal. Chem. 1989, 61, 905; Panja, S.; Chakravorti, S.; Spectrochim. Acta, Part A 2002, 58, 113; Crane, N. J.; Mayrhofer, R. C.; Betts, T. A.; Baker, G. A.; J. Chem. Educ. 2002, 79, 1261; Aicart, E.; Junquera, E.; J. Inclusion Phenom. Macrocyclic Chem. 2003, 47, 161; El-Kemary, M. A.; El-Gezawy, H. S.; J. Photochem. Photobiol., A 2003, 155, 151; Du, X. Z.; Lu, W. H.; Bai, X. Z.; Wang, Y. R.; Deng, H. L.; Hou, J. G.; Spectrosc. Lett. 2005, 38, 569; Al-Sherbini, E. -S. A. M.; Microporous Mesoporous Mater. 2005, 85, 25; Abou-Zied, O. K.; Spectrochim. Acta, Part A 2005, 62, 245.

23. Gelb, R. I.; Schwartz, L. M.; Laufer, D. A.; J. Chem. Soc., Perkin Trans. 2 1984, 15; Ghosh, K. K.; Sharma, P.; J. Dispersion Sci. Technol. 2005, 26, 723; Malta, L. F. B.; Senra, J. D.; Medeiros, M. E.; Antunes, O. A. C.; Supramol. Chem. 2006, 18, 327.

24. Sinisterra, R. D.; Najjar, R.; Alves, O. L.; Santos, P. S.; de Carvalho, C. A. A.; da Silva, A. L. C.; J. Inclusion Phenom. Macrocyclic Chem. 1995, 22, 91; Burgos, A. E.; Sinisterra, R. D.; Augusti, R.; Lago, R. M.; J. Inclusion Phenom. Macrocyclic Chem. 2003, 45, 149; Di Tullio, A.; Reale, S.; De Angelis, F.; J. Mass Spectrom. 2005, 40, 845.

25. Harata, K.; Tsuda, K.; Uekama, K.; Otagiri, M.; Hirayama, F.; J. Inclusion Phenom. Macrocyclic Chem. 1988, 6, 135; Tawarah, K. M.; Wazwaz, A. A.; J. Chem. Soc., Faraday Trans. 1993, 89, 1729; Junquera, E.; Mendicuti, F.; Aicart, E.; Langmuir 1999, 15, 4472; Aicart, E.; Junquera, E.; Int. J. 
Pharm. 1999, 176, 169; Gao, Y. A.; Li, Z. H.; Du, J. M.; Han, B. X.; Li, G. Z.; Hou, W. G.; Shen, D.; Zheng, L. Q.; Zhang, G. Y.; Chem. Eur. J. 2005, 11, 5875; Cabaleiro-Lago, C.; Nilsson, M.; Valente, A. J. M.; Bonini, M.; Söderman, O.; J. Colloid Interface Sci. 2006, 300, 782.

26. Ibrahim, M. S.; Shehatta, I. S.; Al-Nayeli, A. A.; J. Pharm. Biomed. Anal. 2002, 28, 217; Yañez, C.; Salazar, R.; Núñez-Vergara, L. J.; Squella, J. A.; J. Pharm. Biomed. Anal. 2004, 35, 51.

27. Park, J. W.; Lee, S. Y.; Song, H. J.; Park, K. K.; J. Org. Chem. 2005, 70, 9505; Kawamura, M.; Higashi, M.; J. Inclusion Phenom. Macrocyclic Chem. 2005, 51, 11; Yamamoto, T.; Fukui, N.; Hori, A.; Matsui, Y.; J. Mol. Struct. 2006, 782, 60; Adachi, K.; Watarai, H.; Chem. Eur. J. 2006, 12, 4249.

28. de Namor, A. F. D.; Blackett, P. M.; Cabaleiro, M. C.; Alrawi, J. M. A.; J. Chem. Soc., Faraday Trans. 1994, 90, 847; Castronuovo, G.; Niccoli, M.; J. Inclusion Phenom. Macrocyclic Chem. 2005, 53, 69; Lerchner, J.; Kirchner, R.; Seidel, J.; Wählisch, D.; Wolf, G.; König, W. A.; Lucklum, R.; Thermochim. Acta 2006, 445, 98; Castronuovo, G.; Niccoli, M.; Bioorg. Med. Chem. 2006, 14, 3883.

29. Connors, K. A.; Binding Constants: The Measurement of Molecular Complex Stability, Wiley-Interscience: New York, 1987, p. 143-168.

30. Cramer, F.; Saenger, W.; Spatz, H. C.; J. Am. Chem. Soc. 1967, 89, 14.

31. Benesi, H. A.; Hildebrand, J. H.; J. Am. Chem. Soc. 1949, 71, 2703.

32. Sompornpisut, P.; Deechalao, N.; Vongsvivut, J.; Science Asia 2002, 28, 263.

33. Yang, C.; Liu, L.; Mu, T. -W.; Guo, Q. -X.; Anal. Sci. 2000, 16, 537.

34. Ver por exemplo: Bender, M. L.; Komiyama, M.; Cyclodextrin Chemistry, Springer-Verlag: New York, 1978; Komiyama, M.; Bender, M. L. Em The Chemistry of Enzyme Action; Page, M.I., ed.; Elsevier: New York, 1984, cap. 14; Rebek, J., Jr.; Acc. Chem. Res. 1984, 17, 258; D'Souza, V. T.; Bender, M. L.; Acc. Chem. Res. 1987, 20, 146.

35. Komiyama, M.; Bender, M. L.; J. Am. Chem. Soc. 1978, 100, 2259; Gelb, R. I.; Schwartz, L. M.; Cardelino, B.; Fuhrman, H. S.; Johnson, R. F.; Laufer, D. A.; J. Am. Chem. Soc. 1981, 103, 1750.

36. Harrison, J. C.; Eftink, M. R.; Biopolymers 1982, 21, 1153; Cromwell, W. C.; Bystrom, K.; Eftink, M. R.; J. Phys. Chem. 1985, 89, 326.

37. Rekharsky, M. V.; Mayhew, M. P.; Goldberg, R. N.; Ross, P. D.; Yamashoji, Y.; Inoue, Y.; J. Phys. Chem. B 1997, 101, 87.

38. Lipkowitz, K. B.; Chem. Rev. 1998, 98, 1829.

39. Lo Meo, P.; D’Anna, F.; Riela, S.; Gruttadauria, M.; Noto, R.; Org. Biomol. Chem. 2003, 1, 1584 .

40. Tabushi, I.; Kiyosuke, Y. I.; Sugimoto, T.; Yamamura, K.; J. Am. Chem. Soc. 1978, 100, 916.

41. Ross, P. D.; Rekharsky, M. V.; Biophys. J. 1996, 71, 2144

42. Jencks, W. P.; Catalysis in Chemistry and Enzymology, McGraw-Hill: New York, 1969, cap. 8.

43. Eftink, M. R.; Andy, M. L.; Bystrom, K.; Perlmutter, H. D.; Kristol, D S.; J. Am. Chem. Soc. 1989, 111, 6765.

44. Al Omari, M. A.; Zughul, M. B.; Davies, J. E. D.; Badwan, A. A.; J. Pharm. Biomed. Anal. 2006, 41, 857.

45. Charumanee, S.; Titwan, A.; Sirithunyalug, J.; Weiss-Greiler, P.; Wolschann, P.; Viernstein, H.; Okonogi, S.; J. Chem. Technol. Biotechnol. 2006, 81, 523.

46. Csernák, O.; Buvári-Barcza, A.; Samu, J.; Barcza, L.; J. Inclusion Phenom. Macrocyclic Chem. 2005, 51, 59.

47. Buvári-Barcza, A.; Csámpai, A.; Barcza, L.; J. Inclusion Phenom. Macrocyclic Chem. 2002, 42, 209.

48. Connors, K. A.; Chem. Rev. 1997, 97, 1325.

49. Reichardt, C.; Chem. Rev. 1994, 94, 2319; Reichardt, C.; Pure Appl. Chem. 2004, 76, 1903.

50. Dawber, J. G.; Etemad, S.; Beckett, M. A.; J. Chem. Soc., Faraday Trans. 1990, 86, 3725; Catalan, J.; Mena, E.; Meutermans, W.; Elguero, J.; J. Phys. Chem. 1992, 96, 3615; Morley, J. O.; Morley, R. M.; Docherty, R. Charlton, M. H.; J. Am. Chem. Soc. 1997, 119, 10192.

51. Ver por exemplo: Gageiro, V.; Aillón, M.; Rezende, M. C.; J. Chem. Soc. Faraday Trans. 1992, 88, 201; Zanotto, S. P.; Scremin, M.; Machado, C. Rezende M. C.; J. Phys. Org. Chem. 1993, 6, 637; Machado, V. G.; Machado, C.; Nascimento, M. da G.; Rezende, M. C.; Ouim. Nova 1996, 19, 523.

52. Ver por exemplo: Herodes, K.; Leito, I.; Koppel, I.; Rosés, M.; J. Phys. Org. Chem. 1999, 12, 109; da Silva, D. C.; Ricken, I.; Silva, M. A. R.; Machado, V. G.; J. Phys. Org. Chem. 2002, 15, 420; Bevilaqua, T.; da Silva, D. C.; Machado, V. G.; Spectrochim. Acta, Part A 2004, 60, 951; Cavalli, V.; da Silva, D. C.; Machado, C.; Machado, V. G.; Soldi, V.; J. Fluoresc. 2006, 16, 77 .

53. Reichardt, C.; Green Chem. 2005, 7, 339

54. Novaki, L. P.; El Seoud, O. A.; Langmuir 2000, 16, 35; Tada, E. B.; Novaki, L. P.; El Seoud, O. A.; Langmuir 2001, 17, 652; Mchedlov-Petrossyan, N. O.; Vodolazkaya, N. A.; Reichardt, C.; Colloids Surf., A 2002, 205, 215.

55. Venturini, C. de G.; Andreaus, J.; Machado, V. G.; Machado, C.; Org Biomol. Chem. 2005, 3, 1751; Venturini, C. de G.; Dissertação de Mestrado, Universidade Regional de Blumenau, Brasil, 2005.
56. Jara, F.; Mascayano, C.; Rezende, M. C.; Tirapegui, C.; Urzua, A.; J. Inclusion Phenom. Macrocyclic Chem. 2006, 54, 95.

57. Jara, F.; Domínguez, M.; Rezende, M. C.; Tetrahedron 2006, 62, 7817.

58. El-Kemary, M. A.; El-Gezawy, H. S.; El-Baradie, H. Y.; Issa, R. M.; Spectrochim. Acta, Part A 2002, 58, 493.

59. Steel, W. H.; Walker, R. A.; Nature 2003, 424, 296.

60. Lehn, J. -M.; Supramolecular Chemistry, VCH: Weinheim, 1995.

61. Machado, V. G.; Baxter, P. N. W.; Lehn, J. -M.; J. Braz. Chem. Soc. 2001, 12, 431; Lehn, J. -M.; Proc. Natl. Acad. Sci. U. S. A. 2002, 99, 4763; Lehn, J. -M.; Rep. Prog. Phys. 2004, 67, 249.

62. Ver por exemplo: Ikeda, H.; Murayama, T.; Ueno, A.; Org. Biomol. Chem 2005, 3, 4262; Delattre, F.; Woisel, P.; Surpateanu, G.; Cazier, F.; Blach, P.; Tetrahedron 2005, 61, 3939; Lungu, N. C.; Dépret, A.; Delattre, F.; Surpateanu, G. G.; Cazier, F.; Woisel, P.; Shirali, P.; Surpateanu, G.; J. Fluorine Chem. 2005, 126, 385; Kuwabara, T.; Shiba, K.; Ozawa, M.; Miyajima, N.; Suzuki, Y.; Tetrahedron Lett. 2006, 47, 4433.

63. Ver por exemplo: Breslow, R.; Zhang, B. L.; J. Am. Chem. Soc. 1994, 116, 7893; Breslow, R.; Schmuck, C.; J. Am. Chem. Soc. 1996, 118, 6601; Dugas, H.; Bioorganic Chemistry: A Chemical Approach to Enzyme Action, $3^{\text {rd }}$ ed., Springer-Verlag: New York, 1996, p. 345-361; Breslow, R.; Dong, S. D.; Chem. Rev. 1998, 98, 1997; Monteiro, J. B.; Chiaradia, L. D Brandão, T. A. S.; Dal Magro, J.; Yunes, R. A.; Int. J. Pharm. 2003, 267, 93; Brandão, T. A. S.; Dal Magro, J.; Chiaradia, L. D.; Nascimento, M. da G.; Nome, F.; Tato, J. V.; Yunes, R. A.; J. Phys. Org. Chem. 2004, 17, 370; Milovic, N. M.; Badjic, J. D.; Kostic, N. M.; J. Am. Chem. Soc. 2004, 126, 696; Barr, L.; Dumanski, P. G.; Easton, C. J.; Harper, J. B.; Lee, K.; Lincoln, S. F.; Meyer, A. G.; Simpson, J. S.; J. Inclusion Phenom. Macrocyclic Chem. 2004, 50, 19; Marinescu, L.; Molbach, M.; Rousseau, C.; Bols, M.; J. Am. Chem. Soc. 2005, 127, 17578; Barr, L.; Lincoln, S. F.; Easton, C. J.; Supramol. Chem. 2005, 17, 547; Andres, G. O.; Silva, O. F.; de Rossi, R. H.; Can. J. Chem. 2005, 83, 1281; Rousseau, C.; OrtegaCaballero, F.; Nordstrom, L. U.; Christensen, B.; Petersen, T. E.; Bols, M Chem. Eur. J. 2005, 11, 5094; Iglesias, E.; Mini-Rev. Org. Chem. 2005, 2, 237; Annalakshmi, S.; Pitchumani, K.; Eur. J. Org. Chem. 2006, 1034 Marinescu, L. G.; Bols, M.; Angew. Chem., Int. Ed. 2006, 45, 4590; Liu, Y.; Horiuchi, N.; Sueichi, Y.; Yamamoto, S.; J. Inclusion Phenom. Macrocyclic Chem. 2006, 54, 233.

64. Voicescu, M.; Ionita, G.; Vasilescu, M.; Meghea, A.; J. Inclusion Phenom. Macrocyclic Chem. 2006, 54, 217.

65. Abreu, A. R.; Costa, I.; Rosa, C.; Ferreira, L. M.; Lourenço, A.; Santos, P. P.; Tetrahedron 2005, 61, 11986.

66. Reece, D. A.; Ralph, S. F.; Wallace, G. G.; J. Membr. Sci. 2005, $249,9$.

67. Madhavan, N.; Robert, E. C.; Gin, M. S.; Angew. Chem., Int. Ed. 2005 , 44, 7584 .

68. Meindersma, G. W.; van Schoonhoven, T.; Kuzmanovic, B.; de Haan, A. B.; Chem. Eng. Process. 2006, 45, 175.

69. Boyer, P. D.; Angew. Chem., Int. Ed. 1998, 37, 2297; Walker, J. E.; Angew. Chem., Int. Ed. 1998, 37, 2309; Machado, V. G.; Nome, F.; Ouim. Nova 1999, 22, 351; Domingos, J. B.; Longhinotti, E.; Machado, V. G.; Nome, F.; Quim. Nova 2003, 26, 745.

70. Para artigos de revisão sobre o assunto, ver: Nepogodiev, S. A.; Stoddart, J. F.; Chem. Rev. 1998, 98, 1959; Raymo, F. M.; Stoddart, J. F.; Chem. Rev. 1999, 99, 1643; Harada, A.; Acc. Chem. Res. 2001, 34, 456; Schalley, C. A.; Beizai, K.; Vogtle, F.; Acc. Chem. Res. 2001, 34, 465; Lee, J. W Kim, K.; Top. Curr. Chem. 2003, 228, 111; Takata, T.; Kihara, N.; Furusho, Y.; Adv. Polym. Sci. 2004, 171, 1; Menon, S. K.; Guha, T. B.; Agrawal, Y. K.; Rev. Inorg. Chem. 2004, 24, 97; Aricó, F.; Badjic, J. D.; Cantrill, S. J.; Flood, A. H.; Leung, K. C. -F.; Liu, Y.; Stoddart, J. F.; Top. Curr. Chem. 2005, 249, 203; Huang, F. H.; Gibson, H. W.; Prog. Polym. Sci. 2005, 30 982; Wenz, G.; Han, B. H.; Muller, A.; Chem. Rev. 2006, 106, 782.

71. Miyauchi, M.; Kawaguchi, Y.; Harada, A.; J. Inclusion Phenom. Macrocyclic Chem. 2004, 50, 57.

72. Schmitz, S.; Ritter, H.; Angew. Chem., Int. Ed. 2005, 44, 5658.

73. Rusa, C. C.; Wei, M.; Bullions, T. A.; Shuai, X.T.; Uyar, T.; Tonelli, A. E.; Polym. Adv. Technol. 2005, 16, 269.

74. Khodarahmi, R.; Yazdanparast, R.; Int. J. Biol. Macromol. 2005, 36, 191.

75. Yu, S.; Zhao, Y.; Wu, F.; Zhang, X.; Lü, W.; Zhang, H.; Zhang, Q.; Int. J. Pharm. 2004, 281, 11.

76. Xiao, H.; Cezar, N.; J. Colloid Interface Sci. 2005, 283, 406.

77. Dubey, V.; Pandey, L. K.; Saxena, C.; Sep. Purif. Technol. 2006, 50, 45.

78. Aime, S.; Gianolio, E.; Uggeri, F.; Tagliapietra, S.; Barge, A.; Cravotto, G.; J. Inorg. Biochem. 2006, 100, 931.

79. Asanuma, H.; Hishiya, T.; Komiyama, M.; J. Inclusion Phenom. Macrocyclic Chem. 2004, 50, 51; Egawa, Y.; Shimura, Y.; Nowatari, Y.; Aiba, D.; Juni, K.; Int. J. Pharm. 2005, 293, 165.

80. Belyakova, L. A.; Varvarin, A. M.; Lyashenko, D. Y.; Khora, O. V.; Adsorpt. Sci. Technol. 2005, 23, 703. 
81. Scalia, S.; Tursilli, R.; Bianchi, A.; Lo Nostro, P.; Bocci, E.; Ridi, F.; Baglioni, P.; Int. J. Pharm. 2006, 308, 155.

82. Ver por exemplo: Prado, A. G. S.; Quim. Nova 2003, 26, 738; Lenardão, E. J.; Freitag, R. A.; Dabdoub, M. J.; Batista, A. C. F.; Silveira, C. D.; Quim. Nova 2003, 26, 123; da Silva, F. M.; de Lacerda, P. S. B.; Jones, Jr. J.; Quim. Nova 2005, 28, 103

83. Szaniszló, N.; Fenyvesi, É.; Balla, J.; J. Inclusion Phenom. Macrocyclic Chem. 2005, 53, 241.

84. Viglianti, C.; Hanna, K.; de Brauer, C.; Germain, P.; Environ. Pollut. 2006, $140,427$.

85. Baird, C.; Environmental Chemistry, $2^{\text {nd }}$ ed., W.H. Freeman: New York, 1999.

86. Cassez, A.; Ponchel, A.; Bricout, H.; Fourmentin, S.; Landy, D.; Monflier, E.; Catal. Lett. 2006, 108, 209.

87. Fedi, S.; Tremaroli, V.; Scala, D.; Perez-Jimenez, J. R.; Fava, F.; Young, L.; Zannoni, D.; Res. Microbiol. 2005, 156, 201.

88. Ramaseshan, R.; Sundarrajan, S.; Liu, Y. J.; Barhate, R. S.; Lala, N. L.; Ramakrishna, S.; Nanotechnology 2006, 17, 2947.

89. Cathum, S.; Velicogna, D.; Obenauf, A.; Dumouchel, A.; Punt, M.; Brown, C. E.; Ridal, J.; Anal. Bioanal. Chem. 2005, 381, 1491.

90. Klein, C.; Schneider, R. J.; Meyer, M. T.; Aga, D. S.; Chemosphere 2006, $62,1591$.

91. Balmas, V.; Delogu, G.; Sposito, S.; Rau, D.; Migheli, Q.; J. Agric. Food Chem. 2006, 54, 480.

92. Romi, R.; Lo Nostro, P.; Bocci, E.; Ridi, F.; Baglioni, P.; Biotechnol. Prog. 2005, 21, 1724.

93. Arad-Yellin, R.; Tsoucaris, G.; Green, B. S.; Tetrahedron Lett. 2001, 42, 1335.

94. Tsorteki, F.; Bethanis, K.; Pinotsis, N.; Giastas, P.; Mentzafos, D.; Acta Crystallogr., Section B: Struct. Sci. 2005, 61, 207.

95. Villaverde J.; Morillo, E.; Pérez-Martínez, J. I.; Ginés, J. M.; Maqueda C.; J. Agric. Food Chem. 2004, 52, 864; Dignam, C. F.; Randall, L. A.; Blacken, R. D.; Cunningham, P. R.; Lester, S. K. G.; Brown, M. J.; French, S. C.; Aniagyei, S. E.; Wenzel, T. J.; Tetrahedron: Asymmetry 2006, 17, 1199

96. Marini, R. D.; Servais, A. C.; Rozet, E.; Chiap, P.; Boulanger, B.; Rudaz, S.; Crommen, J.; Hubert, P.; Fillet, M.; J. Chromatogr., A 2006, 1120, 102.

97. Wang, P.; Jiang, S.; Liu, D.; Wang, P.; Zhou, Z.; J. Biochem. Biophys. Methods 2005, 62, 219; Ward, T. J.; Anal. Chem. 2006, 78, 3947.

98. Ali, I.; Kumerer, K.; Aboul-Enein, H. Y.; Chromatographia 2006, 63, 295.

99. Bonato, P. S.; Jabor, V. A. P.; de Gaitani, C. M.; Quim. Nova 2005, 28, 683.

100. Ha, P.T.T.; Hoogmartens, J.; Van Schepdael, A.; J. Pharm. Biomed. Anal. 2006, 41,1 .

101. Chen, Y. L.; Jong, Y. J.; Wu, S. M.; J. Chromatogr., A 2006, 1119, 176; Khan, M.; Viswanathan, B.; Rao, D. S.; Reddy, G. S.; J. Pharm. Biomed. Anal. 2006, 41, 1447; Hamoudová, R.; Pospisílová, M.; J. Pharm. Biomed. Anal. 2006, 41, 1463.

102. Juvancz, Z.; Szejtli, J.; Trends Anal. Chem. 2002, 21, 379.

103. Correa, R. A.; Escandar, G. M.; Anal. Chim. Acta 2006, 571, 58.
104. Yang, Y.; Yang, H. F.; Liu, Y. L.; Liu, Z. M.; Shen, G. L.; Yu, R. Q.; Sens. Actuators, B 2005, 106, 632.

105. Rodriguez, J. J. S.; Halko, R.; Rodríguez, J. R. B.; Aaron, J. J.; Anal. Bioanal. Chem. 2006, 385, 525.

106. van Staden, R. I. S.; Rat'ko, A. A.; Talanta 2006, 69, 1049; Stefan, R. I.; van Staden, J. F.; Aboul-Enein, H. Y.; Chirality 1999, 11, 631; Ozoemena, K. I.; Stefan, R. -I.; van Staden, J. F.; Aboul-Enein H. Y.; Sens. Actuators, $B$ 2005, 105, 425 .

107. Szejtli, J. Em Inclusion Compounds; Atwood, J. L.; Davies, J. E. D.; MacNicol, D. D., eds.; Academic Press: London, 1984, vol. 3, cap. 11.

108. de Jesus, M. B.; Pinto, L. de M. A.; Fraceto, L. F.; Takahata, Y.; Lino, A. C. S.; Jaime, C.; de Paula, E.; J. Pharm. Biomed. Anal. 2006, 41, 1428.

109. Uzqueda, M.; Martín, C.; Zornoza, A. Sánchez, M.; Martínez-Ohárriz, M. C.; Vélaz, I.; Pharm. Res. 2006, 23, 980.

110. Cappello, B.; Di Maio, C.; Iervolino, M.; Miro, A.; J. Inclusion Phenom. Macrocyclic Chem. 2006, 54, 289.

111. Schaffazick, S. R.; Guterres, S. S.; Freitas, L. D.; Pohlmann, A. R.; Quim. Nova 2003, 26, 726

112. Duchêne, D.; Ponchel, G.; J. Inclusion Phenom. Macrocyclic Chem. 2002, 44,15 .

113. Lahiani-Skiba, M.; Bounoure, F.; Shawky-Tous, S.; Arnaud, P.; Skiba, M.; J. Pharm. Biomed. Anal. 2006, 41, 1017.

114. Szejtli, J.; Szente, L.; Eur. J. Pharm. Biopharm. 2005, 61, 115.

115. Freudenberg, K.; Cramer, F.; Plieninger, H.; Ger. pat. 8957691953.

116. Binello, A.; Cravotto, G.; Nano, G. M.; Spagliardi, P.; Flavour Frag. J. 2004, 19, 394

117. Del Valle, E. M. M.; Process Biochem. 2004, 39, 1033.

118. Loftsson, T.; Leeves, N.; Bjornsdottir, B.; Duffy, L.; Masson, N.; J. Pharm. Sci. 1999, 88, 1254.

119. Tobitsuka, K.; Miura, M.; Kobayashi, S.; J. Agric. Food Chem. 2005, 53, 5402.

120. Wang, C. X.; Chen, S. L.; Fibres Textiles Eastern Eur. 2005, 13, 41.

121. Uma rápida busca ao Web of Science feita em 05/08/2006 usando-se cyclodextrins como palavra-chave revelou um número superior a 1700 publicações no triênio 2003-2006!

122. Yamanoi, T.; Kobayashi, N.; Takahashi, K.; Hattori, K.; Lett. Drug Des. Discovery 2006, 3, 188

123. Bertelmann, E.; Pleyer, U.; Ophthalmologica 2004, 218, 359.

124. Rudkevich, D.M.; Leontiev, A.V.; Aust. J. Chem. 2004, 57, 713.

125. Jessel, N.; Oulad-Abdeighani, M.; Meyer, F.; Lavalle, P.; Haikel, Y.; Schaaf, P.; Voegel, J. C.; Proc. Natl. Acad. Sci. U. S. A. 2006, 103, 8618.

126. Sortino, S.; Mazzaglia, A.; Scolaro, L.M.; Merlo, F.M.; Valveri, V.; Sciortino, M.T.; Biomaterials 2006, 27, 4256; Memisoglu-Bilensoy, E.; Dogan, A.L.; Hincal, A.A.; J. Pharm. Pharmacol. 2006, 58, 585; Micali, N.; Villari, V.; Mazzaglia, A.; Scolaro, L.M.; Valerio, A.; Rencurosi, A.; Lay, L.; Nanotechnology 2006, 17, 3239.

127. Onclin, S.; Huskens, J.; Ravoo, B. J.; Reinhoudt, D. N.; Small 2005, 1, 852; Crespo-Biel, O.; Ravoo, B. J.; Huskens, J.; Reinhoudt, D. N.; Dalton Trans. 2006, 2737.

128. "Os corpos não agem a menos que eles estejam ligados". 